\title{
Blastomyces dermatitidis
}

National Cancer Institute

\section{Source}

National Cancer Institute. Blastomyces dermatitidis. NCI Thesaurus. Code C117352.

A species of thermally dimorphic fungus in the family Ajellomycetaceae that behaves diversely at different temperatures and is the causative agent of blastomycosis. It is found in the soil in the midwestern and northern United States and Canada. 